\title{
A comparative study of root canal shaping using protaper universal and protaper next rotary files in preclinical dental education
}

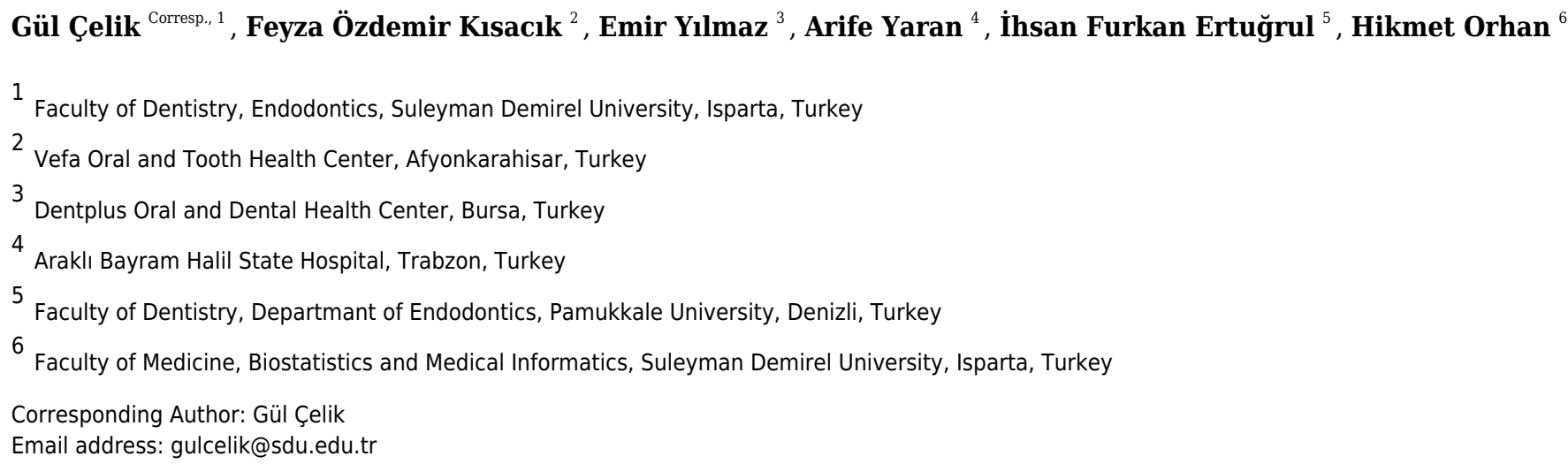

Background. One of Dentistry evolution has occurred in Endodontics due to the advancement of rotary techniques for root canal preparation and its subsequent incorporation into the teaching of Dentistry undergraduates. This research aimed to evaluate the shaping ability of the third-year dental students as their first experience in rotary instrumentation using ProTaper Universal (PTU) and ProTaper Next (PTN) (Dentsply Maillefer) rotary instruments in simulated curved canals. Methods. Forty students instrumented 200 simulated canals with a $40^{\circ}$ curvature in resin blocks according to the manufacturer's instructions with PTU and 39 students 195 canals with PTN files. The canals were prepared at a speed of $300 \mathrm{rpm}$ and using a 16:1 reduction hand-piece powered by an electric motor (Xsmart, Dentsply Maillefer). The final apical preparation was set to F2 for the PTU and X2 for the PTN group. The change in canal curvature was evaluated based on Schneider technique using the AutoCAD 2007 software on post-digital photographs. The incidence of instrument fracture and deformation, the incidence of ledge, the change in working length $(\mathrm{WL})$, and the working time were noted. The data were analyzed with Student's t-test and Chi-Square test at a significance level of 0.05 using SPSS. Results. The PTN maintained the original canal curvature better, resulting in fewer fractures and ledges, and shaped the canals faster than the PTU $\left(\mathrm{P}^{<} 0.05\right)$. The mean curves of the resin canals after the instrumentation for the PTU and PTN groups were $24.03^{\circ} \pm 3.14^{\circ}$ and $25.64^{\circ} \pm 2.72^{\circ}$, respectively. Thirty-three (17.4\%) PTU and $18(9.3 \%)$ PTN files fractured ( $\left.p^{<} 0.05\right)$. Nine (4.5\%) PTU and 2 (2.6\%) PTN deformed ( $\left.p>0.05\right)$. The change in WL after instrumentation was $0.97 \mathrm{~mm} \pm 0.95 \mathrm{~mm}$ in PTU and $0.96 \mathrm{~mm} \pm 0.80 \mathrm{~mm}$ in PTN $(p>0.05)$. 
The mean times were $627 \mathrm{~s} \pm 18 \mathrm{~s}$ for PTU and $379 \mathrm{~s} \pm 18 \mathrm{~s}$ for PTN ( $p^{<} 0.000$ ). Discussion. PTN can be preferred in severe curved of the root canals in terms of maintenance of the original canal curvature, superior instrument fracture and fewer ledges. Even if short training before preparation provided an acceptable level of canal shaping for preclinical students, the use of NiTi rotary instruments should be included in the undergraduate dental curriculum, contributing to an increase in the quality of root canal shaping, and consequently to an improvement of clinical experience of students. 
1 A COMPARATIVE STUDY OF ROOT CANAL SHAPING

2 USING PROTAPER UNIVERSAL AND PROTAPER

3 NEXT ROTARY FILES IN PRECLINICAL DENTAL

4 EDUCATION

5 Gül ÇELIK ${ }^{1}$, Feyza ÖZDEMIR KISACIK², Emir YILMAZ , Arife YARAN ${ }^{4}$, İhsan Furkan

6 ERTUĞRUL ${ }^{5}$, Hikmet Orhan ${ }^{6}$

$7 \quad{ }^{1}$ Faculty of Dentistry, Department of Endodontics, Suleyman Demirel University,

8 Isparta, Turkey

$9 \quad 2$ Vefa Oral and Tooth Health Center, Afyonkarahisar, Turkey

$10{ }^{3}$ Dentplus Oral and Dental Health Center, Bursa, Turkey

$11{ }^{4}$ Araklı Bayram Halil State Hospital, Trabzon, Turkey

$12{ }^{5}$ Faculty of Dentistry, Department of Endodontics, Pamukkale University, Denizli,

13 Turkey

$14{ }^{6}$ Faculty of Medicine, Biostatistics and Medical Informatics, Suleyman Demirel

15 University, Isparta, Turkey

16 Running Title: preparation in preclinical education

17 Corresponding author:

18 Gül Çelik

19 Department of Endodontics

20 Faculty of Dentistry

21 İzmir Demokrasi University,

22 İzmir, Turkey

23 Phone: +905324730823

24 Fax: +902462370607 
Email:

\section{A COMPARATIVE STUDY OF ROOT CANAL SHAPING}

\section{USING PROTAPER UNIVERSAL AND PROTAPER}

\section{NEXT ROTARY FILES IN PRECLINICAL DENTAL}

\section{EDUCATION}

Background. One of Dentistry evolution has occurred in Endodontics due to the advancement of rotary techniques for root canal preparation and its subsequent incorporation into the teaching of Dentistry undergraduates. This research aimed to evaluate the shaping ability of the third-year dental students as their first experience in rotary instrumentation using ProTaper Universal (PTU) and ProTaper Next (PTN) (Dentsply Maillefer) rotary instruments in simulated curved canals. Methods. Forty students instrumented 200 simulated canals with a $40^{\circ}$ curvature in resin blocks according to the manufacturer's instructions with PTU and 39 students 195 canals with PTN files. The canals were prepared at a speed of $300 \mathrm{rpm}$ and using a 16:1 reduction hand-piece powered by an electric motor (Xsmart, Dentsply Maillefer). The final apical preparation was set to F2 for the PTU and X2 for the PTN group. The change in canal curvature was evaluated based on Schneider technique using the AutoCAD 2007 software on post-digital photographs. The incidence of instrument fracture and deformation, the incidence of ledge, the change in working length $(\mathrm{WL})$, and the working time were noted. The data were analyzed with Student's t-test and Chi-Square test at a 
significance level of 0.05 using SPSS. Results. The PTN maintained the original canal curvature better, resulting in fewer fractures and ledges, and shaped the canals faster than the PTU $(\mathrm{P}<0.05)$. The mean curves of the resin canals after the instrumentation for the PTU and PTN groups were $24.03^{\circ} \pm 3.14^{\circ}$ and $25.64^{\circ} \pm 2.72^{\circ}$, respectively. Thirty-three (17.4\%) PTU and 18 (9.3\%) PTN files fractured $(p<0.05)$. Nine (4.5\%) PTU and $2(2.6 \%)$ PTN deformed ( $>00.05)$. The change in $\mathrm{WL}$ after instrumentation was $0.97 \mathrm{~mm} \pm 0.95 \mathrm{~mm}$ in PTU and $0.96 \mathrm{~mm} \pm 0.80 \mathrm{~mm}$ in PTN $(p>0.05) .$. The mean times were $627 \mathrm{~s} \pm 18 \mathrm{~s}$ for PTU and $379 \mathrm{~s} \pm 18 \mathrm{~s}$ for PTN $(\mathrm{p}<0.000)$. Discussion. PTN can be preferred in severe curved of the root canals in terms of maintenance of the original canal curvature, superior instrument fracture and fewer ledges. Even if short training before preparation provided an acceptable level of canal shaping for preclinical students, the use of NiTi rotary instruments should be included in the undergraduate dental curriculum, contributing to an increase in the quality of root canal shaping, and consequently to an improvement of clinical experience of students. 


\section{INTRODUCTION}

68

Cleaning and shaping of the root canal, which must be performed mechanically and biologically, is the most important procedure in root canal treatment. A variety of techniques and instruments have been developed to perform this procedure without generating undesirable clinical results, such as canal straigtening, transportation, ledging, strip perforations, or instrument fractures. The European Society of Endodontics (ESE) has published current articles to lead the undergraduate curriculum in endodontics to improve dental students' theoretical and clinical education (ESE, 2001). ESE believes that undergraduate students should receive preclinical and clinical training to be able to successfully treat uncomplicated anterior premolar and molar teeth (De Moor et al., 2013). Endodontic education needs to be developed in undergraduate programs (Dummer, 1991; Qualtrough \& Dummer, 1997; Unal et al., 2012) and the use of new techniques and devices that have proven to be positive contributions to root canal therapy should be included in undergraduate training programs (Unal et al., 2011).

The technical quality of root fillings, assessed radiographically, performed by undergraduate students using hand instruments was investigated in a meta-analysis (Riberio et al., 2018). The results revealed a low frequency (48.75\%) of acceptable technical quality of root fillings and drew attention to the major procedural errors created 
86 (Riberio et al., 2018). Many studies have been conducted to evaluate the performance

87 of students in curved root canals (Hänni et al., 2003; Arbab-Chirani \& Vulcain 2004;

88

89

90

91

92

Alrahabi, 2015; Unal et al., 2011). Despite the multiple benefits of using NiTi rotary instruments, the step-back technique using stainless steel files is still a conventional teaching method in endodontic programs for undergraduate students in most countries (Alrahabi, 2015). Although students with no experience are reported to be successful in the use of rotary instruments (Unal et al., 2012; Kwak et al., 2016; Brito-Júnior et al., 2014), it is evident that errors can be minimized by the training to be taken in the curriculum. Georgelin-Gurgel et al. (2008) and Alrahabi (2015) reported that manual instrumentation is safer than rotary instrumentation in the hands of inexperienced students. They underlined that acquiring skill in the use of NiTi rotary instrumentation requires specific preclinical training to avert file breakage. Martins et al. (2012) suggested that the use of NiTi rotary instruments should be included in the undergraduate dental curriculum, as this would contribute to an increase in the number of patients assisted, and consequently, improve the students' clinical experience.

Some procedural errors have been minimized after the introduction of the NiTi alloy into endodontics (Walia et al., 1988; Vaudt et al., 2009; Yang et al., 2011). Nevertheless, the fracture of the NiTi rotary root canal instruments suddenly and without any warning creates a disappointment for the dentist (Zuolo \& Walton 1997; Arens et al., 2003; Ankrum et al., 2004). The studies are underway to increase the resistance of the root canal instrument against breakage in order to overcome this problem. A recent novelty of the alloy is the so-called m-wire alloy. The M-Wire material has been shown 
108 to have longer fatigue resistance and lower fracture risk than conventional $\mathrm{NiTi}$ alloy

109 does (Johnson et al., 2008; Montenegro-Santillan et al., 2013).

110 The ProTaper Universal (PTU) system (Dentsply Maillefer, Ballaigues,

111 Switzerland) is currently used by endodontists, and it is one of the most revolving

112 instrument systems researchers have searched for the most (Peters et al., 2003;

113 Schäfer \& Vlassis, 2004; Celik Unal et al., 2006; Yang et al., 2007; Alemam et al.,

114 2017). PTU is nickel titanium (NiTi) rotary system of instruments manufactured with

115 progressive tapering over the length of the cutting blades, convex triangular cross-

116 sections, and noncutting tips. In the PTU system, the file is produced in such a way that

117 it does not cut the ends, and its cross-section is a convex triangle. The taper angle of

118 the file is not constant. This angle increases parabolically starting from the end (Hieawy

119 et al., 2015).

120 The design features of ProTaper Next (PTN, Dentsply Maillefer), made from the

121 new M-Wire alloy, include variable tapers and rectangle sections with a remote center.

122 The M-Wire material has been shown to have longer fatigue resistance and lower

123 fracture risk than conventional NiTi alloy does (Johnson et al., 2008; Montenegro-

124 Santillan et al., 2013). The number of instruments is similar to that of the PTU in terms

125 of the order of use and each instrument. The PTU contains three files (SX, S1, and S2)

126 for the preparation of the coronal and middle thirds and three files (F1, F2, and F3) for

127 the preparation of the apical third. PTN consists of only three files (X1 is \#17/.04, X2 is

$128 \# 25 / .06$, and $X 3$ is \#30/.075), close to the diameters of the files used in the apical third

129 in the PTU system (Pérez-Higueras et al., 2014). 
This study aimed to compare the shaping ability of PTU and PTN rotary

131 instruments used by the third-year dental students inexperienced in any rotary

132 instrumentation techniques in simulated curved canals of resin blocks.

\section{METHODS} preclinical endodontics at the School of the Dentistry of the Suleyman Demirel University, Isparta, Turkey had three 50-min lectures of about the NiTi instruments, their physical properties, and the special constructional features of the files. The present study was based on data obtained from practical courses, which was compulsory for the students to attend. Therefore, there was no need to sign an acceptance form for participation. The results of this study did not affect the course notes of the students.

The students instrumented 16 simulated canals in acrylic resin blocks in the 2014-2015 academic year and 12 extracted human teeth 2015-2016 in the preclinical dental education. The shaping technique was Modified Double Flared Technique using balanced force principle (Saunders \& Saunders, 1992) with stainless steel instrument.

145 The students attended a 2-h lecture on the use of PTU and PTN files two weeks before 146 the end of the term. The study was started in the last week of the term. The students 147 were divided into groups of 10, and an associated professor (G.Ç.) demonstrated the procedures of the shaping of a simulated canal according to the instructions of the manufacturer. A printed script with the manufacturer's step-by-step instructions for the PTU and PTN rotary systems was given to each student. 
The students instrumented a total of 395 simulated resin canals (Endo Training

152 Block 02 taper, REFA 0177; Dentsply Maillefer, CH-1338 Ballaigues, Switzerland). All

153 simulated resin canals had an apical foramen of $0.15 \mathrm{~mm}$, a taper of 0.02 , and an angle

154 of curvature of $40^{\circ}$. Of the 79 students, 40 students assigned randomly instrumented

155200 canals using PTU files and 39 students instrumented 195 canals using PTN files.

156 Each student instrumented five simulated canals using just one of the two systems and

157 only one set instrument. .. The canals for each file system were instrumented to a

158 working length of $16 \mathrm{~mm}(0.5 \mathrm{~mm}$ from the apex $)$ at a speed of $300 \mathrm{rpm}$ and a torque-

159 control level of 2 , using a $16: 1$ reduction handpiece powered by an electric motor

160 (Xsmart, Dentsply Maillefer). Two $\mathrm{mL}$ of distilled water was used as an irrigant at each

161 change of instrument. After the instrumentation, a final rinse with distilled water for 1

162 min was carried out. Each canal was dried using size 25 paper points.

The incidence of fractures in the blocks and instrument deformations It were

recorded. The blocks which instrument fractured were not taken into account when

calculating the curvature and WL change, and incidence of the ledge.. The working time

was calculated starting through the insertion of the first file until the end of the

167 instrumentation, including total active instrumentation, cleaning of the flutes of the

instruments, and irrigation. The final WL of the canals was determined in $\mathrm{mm}$ following

instrumentation of canals. An F2 PTU or X2 PTN file was inserted into the canal and its

WL within the canal measured to the nearest $0.5 \mathrm{~mm}$. The amount of change in WL was

171 determined by subtracting the final length from $16 \mathrm{~mm}$.. Canal straightening and ledge

172 formation were assessed on digital images (Figure 1 and Figure 2). After the canal

173 instrumentation, the images of the resin blocks were obtained with the help of a light 
174 microscope camera (Zeiss Axioskop 2, Münich, Germany) to determine the canal

175 curvature. The images were taken from each block in one direction (mimicking clinical

176 conditions). In these images, canal curvatures were measured by a computer program

177 (AutoCAD 2007) according to Schneider (1971). The change in canal curvature was

178 determined by subtracting the value obtained after instrumentation from 40 degrees. All

179 students were randomly divided into two groups as they are at the same educational

180 level. Therefore, it was accepted that the only variable in the experimental groups was

181 PTU and PTN files. Data were analyzed using SPSS software, version 10.0 (SPSS Inc.,

182 Chicago, USA). The level of significance was set at $5 \%$. Student's t-test was used to

183 evaluate differences in canal straightening, working time, and amount of change in WL.

184 The chi-square test was used to evaluate differences in the incidences of instrument

185 fracture, instrument deformation, while Yates corrected chi-square test was used ledge

186 formation between the groups.

\section{RESULTS}

The PTN preserved the original canal curvature $(\mathrm{P}<0.000)$ better, resulting in

fewer fractures $(p<0.05)$ and ledges $(p<0.000)$, and shaped the canals faster $(P<0.000)$

than the PTU. The mean curvatures of the canals after instrumentation with PTU and

PTN were $24.03^{\circ} \pm 3.14^{\circ}$ and $25.64^{\circ} \pm 2.72^{\circ \circ}$, respectively $(P<0.000)$. The incidence of instrument fracture was $17.4 \%$ (33) for PTU and $9.32 \%$ (18) for PTN $(p<0.05)$. The incidence of instrument deformation was $9(4.5 \%)$ for PTU and 2 (2.6 \%) for PTN

$194(P>0.05)$. The PTN had fewer ledges than PTU $(P<0.000)$. Ledge formation was observed in $33(18.8 \%$ () of the canals in the PTU group, while in $7(4 \%)$ in the PTN group $(P<0.000)$.. There was no statistically significant difference in the preservation of 
197 the $\mathrm{WL}(\mathrm{P}>0.05)$. The mean change in $\mathrm{WL}$ after instrumentation was $0.97 \mathrm{~mm} \pm 0.95 \mathrm{~mm}$

198 in the PTU group and $0.96 \pm 0.80 \mathrm{~mm}$ in the PTN group $(\mathrm{p}>0.05)$ PTN shaped the

199 canals more quickly than PTU $(\mathrm{P}<0.000)$. The mean time in instrumentation of the

200 canals was $627 \mathrm{~s} \pm 28 \mathrm{~s}$ for PTU and $379 \mathrm{~s} \pm 18 \mathrm{~s}$ for PTN $(\mathrm{P}<0.000)($ Table 1$)$.

201

202

\section{DISCUSSION}

The ESE, Education and Scholarship Committee, encourages the use of proven

204

205

206

207

208

209

210

211

212

213

214

215

216

217

218

new tools, techniques, and training resources in endodontics education (Dummer et al., 2013). Updated of the endodontic clinical curriculum is an essential step to having acceptable endodontic treatment, for both general practitioners and specialist dentists. Preclinical exercises are extremely important for the acquisition of this skill (De Moor et al, 2013; Georgelin-Gurgel et al., 2008; Alrahabi, 2015).

This research presents the experiences of the third-year preclinical students in the Faculty of Dentistry of the University of Suleyman Demirel with rotary instruments following training on root canal preparation with hand instruments. Instrumentation techniques with engine-driven instruments are now almost indispensable for root canal treatment beyond popularization in root canal instrumentation. Along with hand instruments, which are indispensable, instrumentation with rotary instruments is also important. Hänni et al. (2003) showed that third-year students can use preclinical course profile 0.04 taper (Dentsply Maillefer, Ballagues, Switzerland) instruments in a satisfactory manner. Moreover, Arbab-Chirani \& Vulcain (2004) in France and AbuTahun et al. (2014) in Jordan reported that there is a consensus on the need for the use 
219 of rotary instruments in undergraduate education. Following this, the use of rotary

220 instruments in the dentistry faculty was added to the curriculum in France.; Kang et al.

221 (2006) reported that the ProFile is the safest, best instrument for root canal shaping for

222 students and beginners. Peru et al. (2006) reported that curved root canals prepared by

223 non-experienced undergraduates with rotary instruments exhibit less procedural errors

224 and require less time than those generated using hand instruments. In addition, Tu et al.

225 (2008) showed that undergraduate students could generate more successful root canal

226 shaping with ProTaper rotary instruments than they can with hand ProTaper

227 instruments. Sonntag et al. (2008) found that preclinical endodontics training varied

228 significantly according to the curriculum, instructor, and course content, and they

229 announced that, as of 2008 , most (63\%) faculties in Germany taught root canal

230 instrumentation with rotary $\mathrm{Ni}-\mathrm{Ti}$ instruments. Unal et al. (2012) reported that third-year

231 students with no experience with rotating instruments were successful in molar root

232 canal preparations after $2 \mathrm{~h}$ of theoretical education about rotary instruments. Brito-

233 júnior et al. (2014) reported that undergraduate students produced lower apical

234 transportation in curved canals with F1 and F2 PTU files. Furthermore, Bruno et al.

235 (2016) stated that the low fracture rates observed in their study indicated that the

236 examined instruments can be used safely by students.

In the literature, there are many different experiments to evaluate the shaping and cleaning of the root canal. Artificial resin models are preferred in many studies because having a standard canal length, curvature, and form (Kum et al., 2000; Unal et al., 2009; Unal et al., 2012). The $\mu \mathrm{CT}$ is emerging in several endodontic research facilities as a nondestructive and accurate method to analyze canal geometry and the relative effects 
242 of shaping techniques (Peters et al., 2003; Peru et al., 2006). As the cost of the $\mu C T$

243 assessment method was high, our study was carried out in acrylic resin blocks.

244 Although this experimental model does not fully reflect the morphology of real human

245 teeth, it can give an idea of relation to relation to the performance of the root canal

246 instrument.

The most frequently encountered case for procedural errors during the preparation

248 of curved root canals is the straightening of the root canals instrument fracture and

249 deformation, and ledge (Nagy et al. 1997). Some of the reasons for these procedural

250 errors are the instrument type and dimension, the type of alloy and the canal curve of

251 before the instrumentation (Parashos \& Messer, 2006; Lambrianidis, 2009). Further, the

252 test material in which the instrumentation is carried out may also affect the test results

253 (Alrahabi \& Zafar, 2018). In our study, PTN $\left(25.64^{\circ}\right)$ maintained original canal curvature

254 better than PTU $\left(24.03^{\circ}\right)(P<0.000)$. The amount of straightening was found to be higher

255 compared with Unal et al.'s (2012) study. The researchers selected the F1 PTU

file as the master apical file. The smaller the size of this file than the F2 PTU file,

257 the less straightening it may have caused. Besides, the shaping ability of the files was

examined in acrylic resin blocks in our study, while Unal et al. (2012) tested in extracted

259 human teeth. Alrahabi \& Zafar (2018) reported that the files show different performance in the extracted human teeth and simulated resin canals.

The second of the most frustrating procedural errors encountered during the

262 instrumentation of curved root canals is the abrupt fracturing and deforming of the

263 instruments. Applying enough force to metal causes the shape of the material to 
264 change, and this shape change is called deformation. After the force is removed, the

265 permanent shape change that cannot be returned to its original state is called plastic

266

267

268

269

270

271

272

273

274

275

276

277

278

279

280

281

282

283

284

285

286

deformation (Thompson 2000). The opening in the grooves manifests the permanent deformation. In this study, deformation was detected under a microscope. The incidence rate of deformation was $4.5 \%$ (9) for PTU and $2.6 \%(2)$ for PTN ( $p>0.05)$.

The incidence rates of fracture were $17.4 \%$ for PTU and $9.3 \%$ for PTN $(p<0.05)$ in our study. Vieira et al. (2008) reported that unexpected instrument fractures in the automatic systems were closely related to the operator's experience. On contrary, it was reported that inexperienced students could shape the root canal as satisfactory (Hänni et al., 2003; Peru et al., 2006; Unal et al., 2012; Brito-Júnior et al., 2014). Bruno et al. (2016) announced that a total of 30 file fractures were noted during the study period; thus, fractures occurred in $0.37 \%$ of total file uses and $2.98 \%$ of all works. The authors attributed a low rate of fractures to some factors. These factors are the use of the F3 ProTaper, the experience of the operator, and supervised treatment by expert endodontists. Also, Bruno et al. (2016) designed this study under clinical circumstances. Therefore, since the study included all tooth types, the average curvature of the teeth could be assumed to be less than 40 degrees. Besides, working on more curved canals and acrylic resin blocks instead of real teeth could be increased the numbers of instrument fractures and deformations. One of the disadvantages of the use of rotary canal instruments in resin blocks is that they heat the resin while the instruments are in operation, and this heat causes the resin to soften. This heat can also cause the canal instrument to bind to and become entangled in the softened resin, thereby breaking the instrument (Baumann \& Roth, 1999; Kum et al., 2000). The choice of acrylic resin 
287 blocks for standardization is also a limitation of this study. Nevertheless, in a study by

288 Alemann et al. (2017) comparing the shaping abilities of the PTU and PTN instruments

289 in S-shaped canals, the students were more successful. This difference may be due to

290 their use of aqueous lubricant during the preparation. Lubrication usually helps prevent

291 fracture of the instrument during root canal preparation by helping the instrument work

292 in the canal without being forced (Zehnder 2006). We did not use lubricants in our

293 study; we only used distilled water for irrigation. An aqueous lubricant has been shown

294 to be more effective than a gel-type lubricant. A lubricant may exert a physical effect by

295 floating debris away from the rotating instrument. In addition, chemical additives may

296 act on the root canal dentin to facilitate instrumentation (Peters et al., 2005,; Boessler et

297 al., 2007). In our study, this difference between PTU and PTN in terms of instrument

298 fracture and instrument deformation can be due to the different levels of flexibility of the

299 instruments. While PTU is produced from a conventional NiTi alloy, PTN is produced

300 from the more flexible M-Wire. Furthermore, The PTN instruments have an innovative

301 off centered rectangular cross-section that gives the file a snake-like swaggering

302 movement as it progresses through the root canal. The manufacturer claims that this

303 asymmetric rotary motion of ProTaper Next allows achieving fully tapered canals with

304 fewer numbers of files (Tulsa Dental Specialties 2017). In addition, the X2 of PTN has

305 an apical cone of 0.06 , while PTU's F2 instrument exhibits a constant taper from D1 to

306 D3 (0.08) (Alemam et al., 2017).

A ledge is defined as a deviation from the original canal curvature within the apical

308 third which creates or starts to create a new canal at a tangent to the original canal

309 (Nagy et al. 1997). In our study, ledges occurred in 19\% of the canals prepared with 
310 PTU, whereas ledges formed in $4 \%$ of PTN cases. One of the reasons why PTN files

311 produce fewer ledges than PTU files can be the superior properties of the m-wire alloy.

312 The alloy structure and cross-sectional shape of the PTU system's F1 and F2

313 instruments will result in a hardened instrument that can cause more ledges to occur

314 than arise in PTN. Furthermore, Alrahabi \& Zafar (2018) considered contributing to the

315 snake-like, swaggering movements of the files during advancement into the root canal.

316 This movement serves to minimize the engagement between the file and dentin.

317 Reduced engagement limits any undesirable taper lock, the screw effect, and the torque 318 on any given file (Haapasalo \& Shen (2013).

\section{CONCLUSIONS}

320 Within the limitations of this study, the PTN can be preferred in severe curvedof the root

321 canals in terms of maintenance of the original canal curvature, superior fracture, and

322 fewer ledges. Even if short training before preparation provides an acceptable level of

323 canal shaping for preclinical students, the use of NiTi rotary instruments should be

324 included in the undergraduate dental curriculum, contributing to an increase in the

325 quality of root canal shaping, and consequently the improvement of clinical experience

326 of students.

\section{ACKNOWLEGDEMENTS}

328 The authors thank Dentsply ${ }^{\circledR}$ for the root canal files and resin blocks used in this study. 
331 Abu-Tahun I, Al-Rabab'ah MA, Hammad M, Khraisat A. 2014. Technical quality of root

332 canal treatment of posterior teeth after rotary or hand preparation by fifth year undergraduate students, The University of Jordan. Australian Endodontic Journal. 40:123-30. DOI 10.1111/aej.12069.

335

Arbab-Chirani R, Vulcain JM. 2004. Undergraduate teaching and clinical use of rotary nickel-titanium endodontic instruments: a survey of French dental schools. International Endodontic Journal. 37:320-4. DOI 10.1111/j.01432885.2004.00805.x.

Alemam AAH, Dummer PMH, Farnell DJJ. 2017. A Comparative Study of ProTaper Universal and ProTaper Next Used by Undergraduate Students to Prepare Root Canals. Journal of Endodontics. 43:1364. DOI 10.1016/j.joen.2017.03.038.

Alrahabi M. 2015. Comparative study of root-canal shaping with stainless steel and rotary NiTi files performed by preclinical dental students. Technol Health Care. 23):257-65. DOI 10.3233/THC-150895.

Alrahabi M, Zafar MS. 2018. Assessment of apical transportation caused by nickeltitanium rotary systems with full rotation and reciprocating movements using extracted teeth and resin blocks with simulated root canals: A comparative study. Nigerian Journal of Clinical Practice. 21:772-777. DOI 10.4103/njcp.njcp_200_17.

Ankrum MT, Hartwell GR, Truitt JE. 2004. K3 Endo, ProTaper, and ProFile systems: breakage and distortion in severely curved roots of molars. Journal of Endodontics.30:234-7. DOI 10.1097/00004770-200404000-00013 
353 Arens F C, Hoen M M, Steiman H R, Dietz G C. 2003. Evaluation of single-use rotary

354 nickel-titanium instruments. Journal of Endodontics. 29: 664-666.

355

356

357

358

359

360

361

362

Baumann MA, Roth A. 1999. Effect of experience on quality of canal preparation with rotary nickel-titanium files. Oral Surgery, Oral Medicine, Oral Pathology, Oral Radiology, and Endodontology. 88:714-8. DOI 10.1016/S1079-2104(99)700156.

Boessler C, Peters OA, Zehnder M. 2007. Impact of lubricant parameters on rotary instrument torque and force. Journal of Endodontics. 33:280-3. DOI 10.1016/j.joen.2006.11.007

Brito-Júnior M, Faria-E-Silva AL, Camilo CC, Pereira RD, Braga NM, Sousa-Neto MD. 2014. Apical transportation associated with ProTaper® Universal F1, F2 and F3 instruments in curved canals prepared by undergraduate students. Journal of Applied Oral Science. 22: 98-102. DOI 10.1590/1678-775720130464.

Bruno FA, Nunes E, Horta MC, da Fonseca AM, Silveira FF. 2016. Importance of rotary systems in dental care by undergraduate students in patients of a public health service of Belo Horizonte. Journal of Clinical and Experimental Dentistry. 8:e603. DOI 10.4317/jced.52663.

Celik Unal G, Kececi AD, Ureyen Kaya B. 2006. Comparison of the shaping abilities of two rotary and a hand instruments in simulated root canals. Acta Odontologica Turcica. 23:11-6.

De Moor R, Hülsmann M, Kirkevang LL, Tanalp J, Whitworth J. 2013. Undergraduate curriculum guidelines for endodontology. International Endodontic Journal. 46:1105-14. DOI 10.1111/iej.12186. 
376 Dummer PM. 1991.Comparison of undergraduate endodontic teaching programmes in

377

378

379

380

381

382

383

384

385

386

387

388

389

390

391

392

393

394

395

396

397 the United Kingdom and in some dental schools in Europe and the United States. International Endodontic Journal. 24: 169-77. DOI 10.1111/j.13652591.1991.tb00127.x.

European Society of Endodontology. 2001.Undergraduate curriculum guidelines for endodontology. International Endodontic Journal. 34: 574-80.

Georgelin-Gurgel M, Devillard R, Lauret ME, Diemer F, Calas P, Hennequin M. 2008. Root canal shaping using rotary nickel-titanium files in preclinical teaching. Odonto-stomatologie Tropicale. 31:5-11.

Haapasalo M, Shen Y. 2013. Evolution of nickel-titanium instruments: from past to future. Endodontic Topics;29:3-17.

Hänni S, Schönenberger K, Peters OA, Barbakow F. 2003. Teaching an engine-driven preparation technique to undergraduates: initial observations. International Endodontic Journal. 36:476-82. DOI 10.1046/j.1365-2591.2003.00677.x.

Hieawy A, Haapasalo M, Zhou H, Wang ZJ, Shen Y. 2015. Phase Transformation Behavior and Resistance to Bending and Cyclic Fatigue of ProTaper Gold and ProTaper Universal Instruments. Journal of Endodontics.41:1134-8. DOI 10.1016/j.joen.2015.02.030.

Kang MS, Kim HC, Hur B, Park JK. 2006. Comparison Of Shaping Ability of Rotary Ni-Ti File Systems Used by Undergraduates. Restorative Dentistry \& Endodontics.; 31:1-10. DOI 10.5395/JKACD.2006.31.1.001. 
398 Kum KY, Spängberg L, Cha BY, II-Young J, Seung-Jong L, Chan-Young L. 2000.

399 Shaping ability of three ProFile rotary instrumentation techniques in simulated

400 resin root canals. Journal of Endodontics.;26:719-23. DOI 10.1097/00004770-

401 $200012000-00013$.

402

403

404

405

406

407

408

409

410

411

412

413

414

415

416

Nagy CD, Bartha K, Bernáth M, Verdes E, Szabó J. 1997. The effect of root canal students' perceptions about the endodontic treatments performed using $\mathrm{NiTi}$ rotary instruments and hand stainless steel files. Brazilian Dental Journal.

Lambrianidis T. 2009. Ledging and blockage of rootcanals during canal preparation:causes, recognition, prevention,management, and outcomes. Endodontic Topics 2009, 15, 56-7474.

Martins RC1, Seijo MO, Ferreira EF, Paiva SM, Ribeiro Sobrinho AP. 2012. Dental 23:729-36. DOI 10.1590/S0103-64402012000600018.

417

418 Parashos P, Messer HH. 2006. Rotary NiTi instrument fracture and its consequences. 419 Journal of Endodontics. 32:1031-43. DOI 10.1016/j.joen.2006.06.008 
420 Pérez-Higueras JJ, Arias A, de la Macorra JC, Peters OA. 2014. Differences in cyclic 421 fatigue resistance between ProTaper Next and ProTaper Universal instruments at different levels. Journal of Endodontics. 40:1477-81. DOI 10.1016/j.joen.2014.02.025.

Peru M, Peru C, Mannocci F, Sherriff M, Buchanan LS, Pitt Ford TR. 2006. Hand and nickel-titanium root canal instrumentation performed by dental students: a microcomputed tomographic study. European Journal of Dental Education. 10:52-9. DOI 10.1111/j.1600-0579.2006.00395.x

Peters Cl, Schönenberger K, Barbakow F. 2003. ProTaper rotary root canal preparation: effects of canal anatomy on final shape analysed by micro CT. International Endodontic Journal. 36:86-92. DOI 10.1046/j.1365-2591.

.Peters OA, Boessler C, Zehnder M. 2005. Effect of liquid and paste-type lubricants on torque values during simulated rotary root canal instrumentation. International Endodontic Journal. DOI 38:223-9. 10.1111/j.1365-2591.2005.00937.x

Qualtrough AJ, Dummer PM. 1997. Undergraduate endodontic teaching in the United Kingdom: an update. International Endodontic Journal. 30: 234-9. DOI 10.1046/j.1365-2591.1997.t01-1-00072.x.

Ribeiro DM, Réus JC, Felippe WT, Pacheco-Pereira C, Dutra KL, Santos JN Porporatti, AL, De Luca Canto G. 2018. Technical quality of root canal treatment performed by undergraduate students using hand instrumentation: a meta-analysis. International Endodontic Journal.51:269-283. doi: 10.1111/iej.12853. 
441 Saunders WP, Saunders EM. 1992. Effect of noncutting tipped instruments on the

442

443

444

445

446

447

448

449

450

451

452

453

454

455

456

457

458

459

460

461

462

463 quality of root canal preparation using a modified double-flared technique. Journal of Endodontics. 18: 32-6. DOI 10.1016/S0099-2399(06)81140-4.

Schäfer E, Vlassis M. 2004. Comparative investigation of two rotary nickel-titanium instruments: ProTaper versus RaCe. Part 1. Shaping ability in simulated curved canals. International Endodontic Journal. 37: 239-48. DOI 10.1111/j.01432885.2004.00783.x.

Schneider SW. 1971. A comparison of canal preparations in straight and curved root canals. Oral Surgery, Oral Medicine, Oral Pathology and Oral Radiology.32:2715.

Sonntag D, Bärwald R, Hülsmann M, Stachniss V. 2008. Pre-clinical endodontics: a survey amongst German dental schools. International Endodontic Journal. 41:863-8. DOI 10.1111/j.1365-2591.2008.01438.x.

Thompson SA. 2000. An overview of nickel-titanium alloys used in dentistry. International Endodontic Journal. 33:297-310. DOI 10.1046/j.13652591.2000.00339.x

Tu MG1, Chen SY, Huang HL, Tsai CC. 2008. Endodontic shaping performance using nickel-titanium hand and motor ProTaper systems by novice dental students. Journal of the Formosan Medical Association. 107:381-8. DOI 10.1016/S09296646(08)60103-5.

Tulsa Dental Specialties. Protaper Universal. Directions for use (2017) http://www.tulsadentalspecialties.com/Libraries/Tab_ContentEndo_Access_Shaping/DFUPTNF_Rev1_10-ProTaperNext_DFU.sflb.ashx . 
464 Unal GC, Kececi AD, Kaya BU, Tac AG. 2011. Quality of root canal fillings performed by 465 undergraduate dental students. European Journal of Dentistry. 5:324-30.

466 Unal GC, Maden M, Orhan EO, Sarıtekin E, Teke A. 2012. Root canal shaping using 467 rotary nickel-titanium files in preclinical dental education in Turkey. Journal of 468 Dental Educutaion. 76:509-13.

469 Unal G.C, Maden M, Savgat A, Orhan EO. 2009 "Comparative investigation of 2 rotary 470 nickel-titanium instruments: protaper universal versus protaper", Oral Surgery Oral Medicine Oral Pathology Oral Radiology and Endodontology (ISI), 886-892 pp. DOI 10.1016/j.tripleo.2009.01.010.

473

474

475

476

477

478

479

480

481

482

483

484 485

Vaudt J, Bitter K, Neumann K, Kielbassa AM. 2009. Ex vivo study on root canal instrumentation of two rotary nickel-titanium systems in comparison to stainless steel hand instruments. International Endodontic Journal. 42:22-33. DOI 10.1111/j.1365-2591.2008.01489.x.

Walia HM, Brantley WA, Gerstein H. 1988. An initial investigation of the bending and torsional properties of Nitinol root canal files. Journal of Endodontics;14:346-51. DOI 10.1016/s0099-2399(88)80196-1.

Vieira EP, França EC, Martins RC, Buono VT, Bahia MG.. 2008. Influence of multiple clinical use on fatigue resistance of ProTaper rotary nickel-titanium instruments. International Endodontic Journal. 41:163-72. DOI 10.1111/j.13652591.2007.01336.x.

Yang GB, Zhou XD, Zheng YL, Zhang H, Shu Y, Wu HK. 2007. Shaping ability of progressive versus constant taper instruments in curved root canals of extracted 
teeth. International Endodontic Journal. 40: 707-14. DOI 10.1111/j.1365-

487 2591.2007.01296.x.

488

489

490

491

492

493

494

495
Yang G, Yuan G, Yun X, Zhou X, Liu B, Wu H. 2011. Effects of two nickel-titanium instrument systems, Mtwo versus ProTaper universal, on root canal geometry assessed by micro-computed tomography. Journal of Endodontics. 37:1412-6. DOI 10.1016/j.joen.2011.06.024.

Zehnder M. 2006. Root canal irrigants. Journal of Endodontics. 32:389 -98. DOI 10.1016/j.joen.2005.09.014.

Zuolo M L, Walton R E. Instrument deterioration with usage: nickel-titanium versus stainless steel. Quintessence Int 1997; 28: 397-402. 


\section{Table $\mathbf{1}$ (on next page)}

The canal curvature, the change in WL, the working time, the fractured instrument and deformed instrument, and the ledge based on the groups after instrumentation

SD: standard deviation, PTU: ProTaper Universal, PTN: Protaper Next, N: the number of sample 


\begin{tabular}{|c|c|c|c|c|c|c|}
\hline & PTU & $\mathrm{N}$ & PTN & $\mathrm{N}$ & total & $P$ value \\
\hline $\begin{array}{l}\text { The degree and SD of } \\
\text { canal curvature }\end{array}$ & $24.03^{\circ} \pm 3.14^{\circ}$ & 174 & $25.64^{\circ} \pm 2.72^{\circ}$ & 176 & 395 & $0.000 * * *$ \\
\hline $\begin{array}{l}\text { Amount of change and } \\
\text { SD in } W L(\mathrm{~mm})\end{array}$ & $0.97 \pm 0.95$ & 155 & $0.96 \pm 0.80$ & 174 & 395 & 0.99 \\
\hline $\begin{array}{l}\text { Working time and SD } \\
\text { (s) }\end{array}$ & $627 \pm 28$ & 200 & $379 \pm 18$ & 195 & 395 & 0.000 \\
\hline $\begin{array}{l}\text { The number and } \\
\text { percent of the canal } \\
\text { with fractured } \\
\text { instrument }\end{array}$ & $\begin{array}{l}17.4 \% \\
(n=33)\end{array}$ & 190 & $\begin{array}{l}9.32 \% \\
(n=18)\end{array}$ & 194 & 395 & $0.020 *$ \\
\hline $\begin{array}{l}\text { The percent of } \\
\text { deformed instrument }\end{array}$ & $\begin{array}{l}4.5 \% \\
n=9\end{array}$ & 200 & $\begin{array}{l}2.6 \% \\
n=2\end{array}$ & 78 & 278 & 0.403 \\
\hline The percent of ledge & $\begin{array}{l}18.8 \% \\
n=33\end{array}$ & 176 & $\begin{array}{l}4 \% \\
n=7\end{array}$ & 176 & 352 & $0.000 * * *$ \\
\hline
\end{tabular}

1 
Figure 1

Measurement of the canal curvature on the images captured by stereo microscope after instrumentation

a: degree of curvature according to Schneider (1971) 


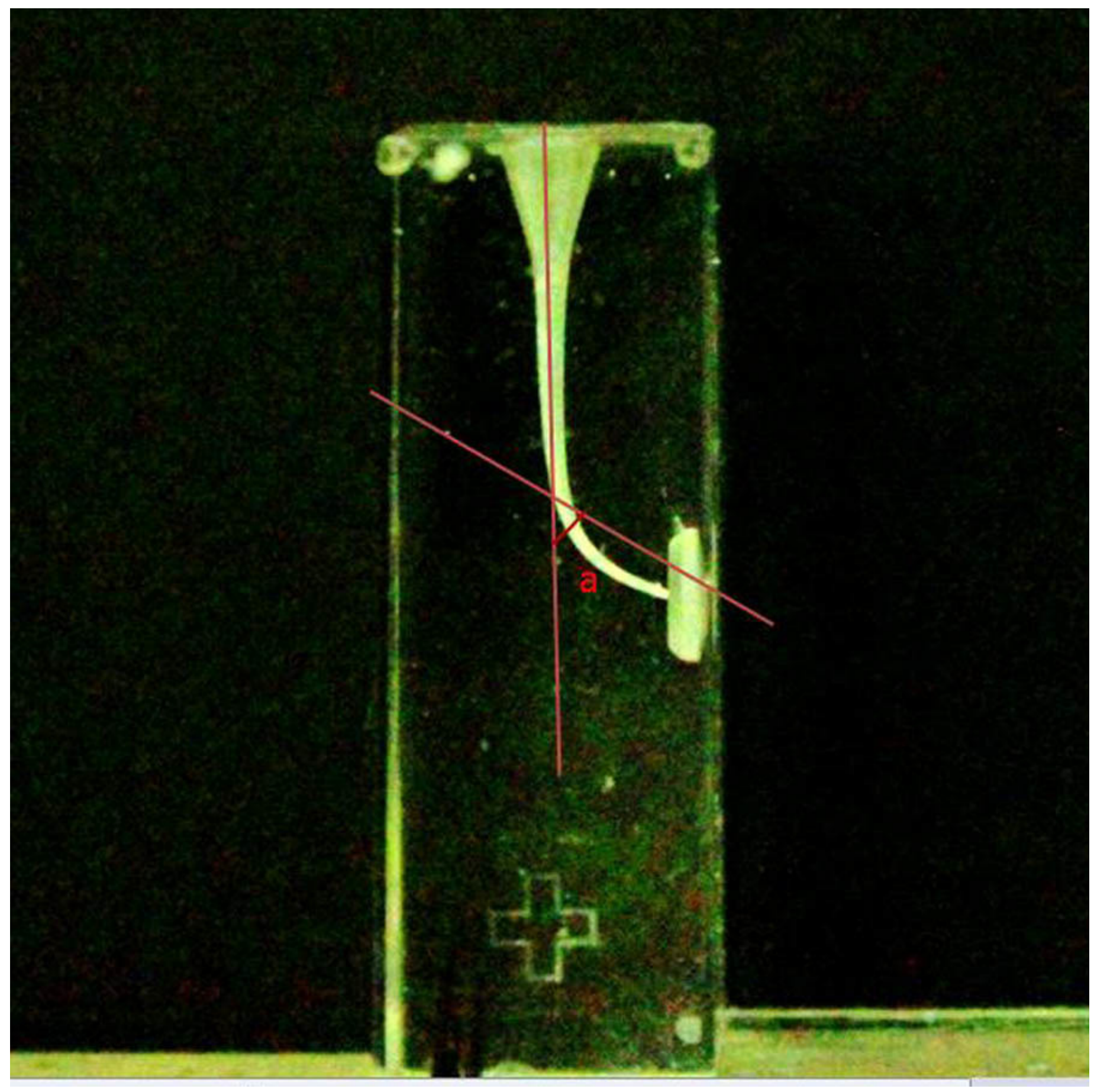


Figure 2

Ledge formation at the beginning of the curvature associated with a marked loss of working length

The arrow indicates the ledge. 


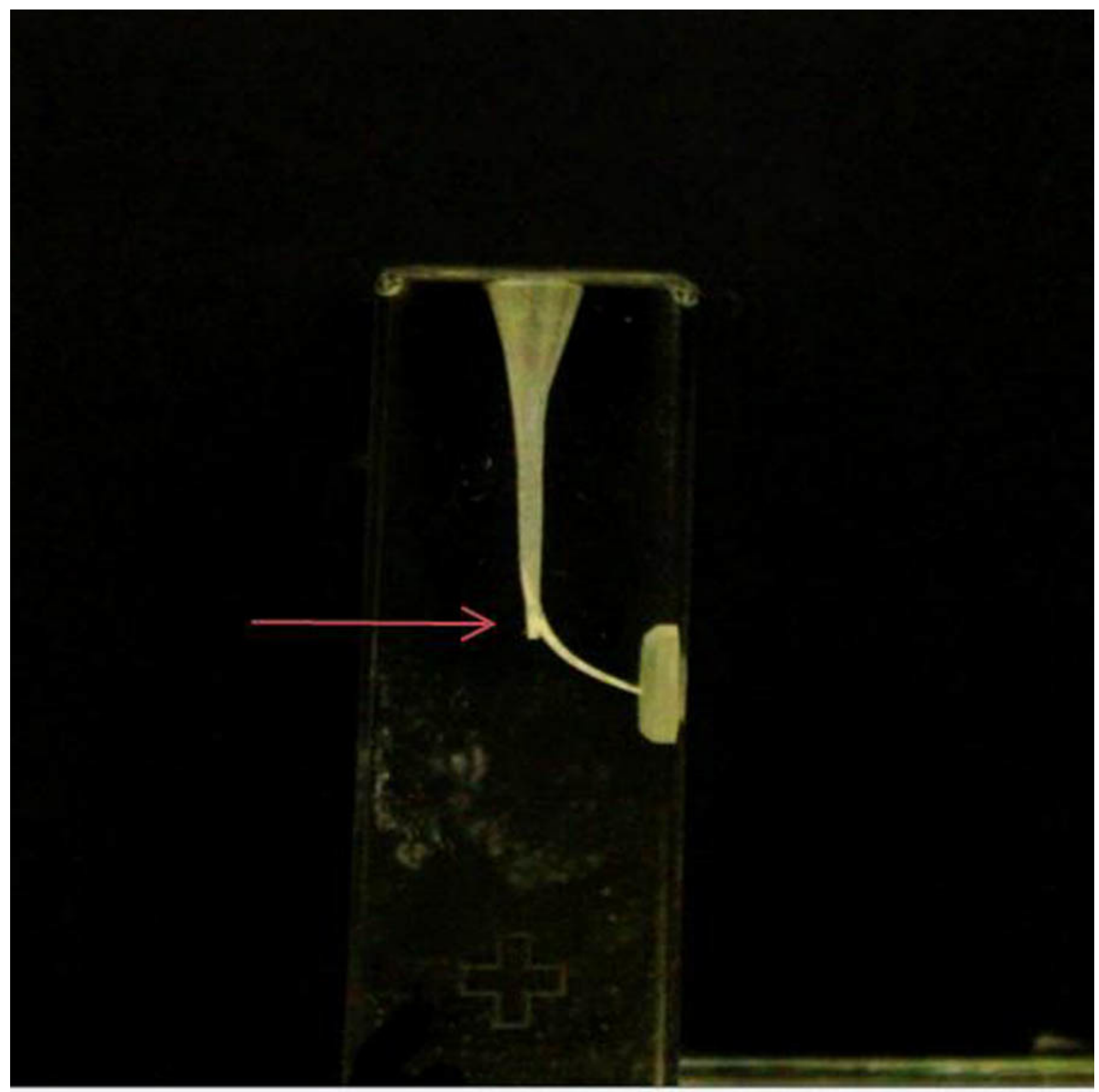

